\title{
High-low Strategy of Portfolio Composition using Evolino RNN Ensembles
}

\author{
Jelena Stankeviciene, Nijole Maknickiene, Algirdas Maknickas
}

\author{
Vilnius Gediminas Technical University \\ Sauletekio av., 11, 10223, Vilnius \\ E-mail.jelena.stankeviciene@vgtu.lt; nijole.maknickiene@vgtu.lt; algirdas.maknickas@vgtu.lt
}

cross $^{\text {ref }}$ http://dx.doi.org/10.5755/j01.ee.28.2.15852

\begin{abstract}
Strategy of investment is important tool enabling better investor's decisions in uncertain finance market. Rules of portfolio selection help investors balance accepting some risk for the expectation of higher returns. The aim of the research is to propose strategy of constructing investment portfolios based on the composition of distributions obtained by using highlow data. The ensemble of 176 Evolino recurrent neural networks (RNN) trained in parallel investigated as an artificial intelligence solution, which applied in forecasting of financial markets. Predictions made by this tool twice a day with different historical data give two distributions of expected values, which reflect future dynamic exchange rates. Constructing the portfolio, according to the shape, parameters of distribution and the current value of the exchange rate allows the optimization of trading in daily exchange-rate fluctuations. Comparison of a high-low portfolio with a close-toclose portfolio shows the efficiency of the new forecasting tool and new proposed trading strategy.
\end{abstract}

Keywords: Finance Markets; Evolino, High-Low Strategy; Investment Portfolio; Prediction.

\section{Introduction}

Decisions about investment or speculations are made in rapidly changing and uncertain financial markets. The prediction of financial markets is one of most difficult issues but it is very important for government and privatesector investment.

Prediction is one of the most complex processes, which is often limited to attempting to guess the market trend, direction, or just a logical decision to 'buy' or 'sell' depending on the respective success probability. A stochastic approach to the assessment of the financial market of the future requires a decision to be taken to assess the probabilities of success and loss. Expected distribution values contain enough information about financial market changes in the future.

The success of investment on financial markets for the most part depends on the prediction tool, strategy, analytic techniques, risk diversification through investment portfolios and intuition of the investor. The connection of these factors into a single system allows the expectation of efficient trading on financial markets. One of the ways to improve the prediction process is by using artificial intelligence.

Our prediction model has been improved from a single Evolino recurrent neural network (RNN) to an ensemble of 176 elements. Its forecasting results have evolved from a single prediction to the distribution of expected values, or even the distribution composition. High-low distributions are predictions based on maximal and minimal data. They define the bands of the exchange-rate changes over a period of time, within a certain probability

This research seeks to integrate the principles of modern portfolio theory with an investor support system for based on evolutionary recurrent neural networks. The portfolio selection based on distributions of expected values is more stochastically informative than a portfolio based on single expected values. The aim of the research is to propose methods of constructing investment portfolios based on the distribution composition of high-low expected values and to compare it to the close-to-close method. Developed new strategy was tested in a dynamic currency market in real-time demo platform.

\section{Literature Review}

Artificial intelligence systems based on neural networks, genetic algorithms, fuzzy logic, agent systems and its hybrids are used successfully to forecast chaotic processes such as finance markets.

Many researchers have used various methods and various techniques for stock market prediction using artificial neural networks (ANN). Gan et al.'s (2013) paper provided a review of the applications of ANN in stock market prediction, in order to determine what can be done in the future. Aguilar-Rivera et al. (2015) present a review of the application of evolutionary computation methods for solving financial problems. Campbell et al. (2015) and Wu et al. (2015) combined three sole prediction models and demonstrated greater forecast accuracy than a single model. Chakraborty et al. (2016) investigated learning rules optimized in an adaptive fashion using a hybrid neural learning mechanism.

Artificial intelligence system modelling, using properly chosen architecture, can create new opportunities for financial market forecasting. RNN ensemble forecasts are more accurate than individual RNNs. In Zhou et al. (2002), the relationship between the ensemble and its component neural networks is analysed. Authors proposed ensemble from twelve RNN, named GASEN, which inspired the better compliance with the theory. Nguen \& Chan (2004) found the opposite sightings: the ensemble of 1-5 neural 
networks does not guarantee better results, better error. Researches of separate cases have argued that model with two neural networks did not perform better than the singleneural network. Garcia-Pedrajas et al. (2005) proposed a general framework for designing neural network ensembles by means of cooperative co-evolution. The proposed model has two main objectives: first, the improvement of the combination of the trained individual networks; and second, the cooperative evolution of such networks, encouraging collaboration among them, instead of the separate training of each network. An ensemble of tree individual neural networks was proposed by Siwek et al. (2009). Investigation of created ensemble showed significant improvement of performance parameters with comparison with single neural network. Uchigaki et al. (2012) proposed a prediction technique with aim to improve the prediction accuracy of cross-project prediction. An ensemble of simple regression models was tested by 132 combinations of cross-project predictions and datasets of 12 projects.

Accurate prediction using artificial intelligence creates the right conditions for the management and proper allocation of assets. Ziemba \& Vickson (1975) introduced stochastic programming and showed why it is more suitable then static approaches for asset or liability management. A number of techniques such as single period mean-variance, dynamic stochastic control, stochastic dynamic programming were investigated and adapted for the financial market (Ziemba \& Mulvey, 1998).

Most common forecasting technique of assets (stock prices or currency exchange rates), is point prediction. But future is always uncertain and gives for investor several opportunities with different probabilities. For this reason the adequate portfolio model is used, developed by Rutkauskas (2000), which is an amplification of Markowitz's (1952) portfolio model. The adequate portfolio conception is based on paradigm that the future is distribution of possibilities. Author of adequate portfolio argues that portfolio return possibilities should be expressed as a probability distribution.

The portfolio return possibilities usually do not conform to normal probability distribution forms and portfolio building based on parameters of probability distribution is especially important. The initial concept of an adequate portfolio and its analysis was also investigated in the scientific works of A.V. Rutkauskas and his co-authors (Rutkauskas 2012; Rutkauskas et al., 2008, 2010, Rutkauskas \& Stasytyte, 2011). Rimeh et al. (2013) proposed scenario generation, which helps the decision-maker to solve a stochastic goal-programming model for a portfolio-selection problem. Dupacova \& Kopa (2014) proposed a probability distribution rules to derive a new robust first order stochastic dominance portfolio efficiency test.

Historical information as a basis for investment decisions is very important for the investor. Traditionally, the opening and closing prices are used for forecasting financial markets. But extremes - maximum and minimum may provide additional information on the price behaviour in the future. Lozza et al. (2011) proposed a comparison of portfolio-selection strategies that used market stochastic bounds. Horst et al. (2012) defined a class of stochastic volatility models that used opening and closing prices, along with the minimum and maximum prices within a trading period, to infer the dynamics underlying the volatility process of asset prices. Corwin \& Schultz (2012) used highlow daily data for developing a bid-ask spread estimator. The model proposed by Caporin et al, (2013), captures two fundamental patterns of high and low prices: their cointegrating relationship and the long memory of their difference, which is a measure of volatility.

Expected value distribution, its shape and parameters provide investors with additional information about the financial market trends. Gabaix et al. (2003) used power laws to describe histograms of relevant financial fluctuations, such as fluctuations in stock price, trading volume and the number of trades. Hautsch et al. 's (2013) model, applied to high-frequency cumulated trading volumes of both liquid and illiquid NYSE stocks, was able to correctly predict future distributions. Rocco (2014) stated that the best and most informative risk measure for the returns on a financial asset was given by the whole tail of the distribution of those returns. In general, this distribution is unknown or difficult to deal with. The information is contained in the tail of the distribution in a single number and so is much easier to deal with, providing a suitable tool for decision-making. The availability of parametric approaches of the distributions allows for projections and forecasting of extreme events.

Some authors investigated the anomalies of the financial markets. Zaremba et al. (2015) investigated the reverse character of the low-price anomaly and the underperformance of lottery stocks. Li and Miller (2015) explained several puzzling facts about exchange rates by focusing on foreign-exchange-market inefficiency. Kvietkauskiene and Maknickiene (2015), and Leangarun et al. (2016) investigated manipulations in the exchange market.

Portfolio construction with incomplete probabilities information was investigated by Inuiguchi and Ramik, (2000), and Tanaka et al. (2000). Adcock (2010) proposed a multivariate model for the probability distribution of asset returns. Minimax bounds for fuzzy portfolio selection was used by Chen et al. (2011), and by Huang (2011) for robust portfolio selection. Liesio \& Salo (2012) proposed a method of portfolio selection, which used incomplete information about scenario probabilities and utility functions, and identified all the non-dominant project portfolios in view of this information. Chourmouziadis and Chatzoglou (2016) improved trading results by using buy and hold strategies, based on a fuzzy system.

Innovative artificial intelligence algorithms, modern portfolio theory and stochastic forecasts evaluation can be used effectively to trade in the financial markets

\section{Predictions Model Based on Artificial Intelligence}

Our forecasting tool is based on prediction capabilities of Long Short-Term Memory (LSTM). Wierstra et al. (2005) and Schmidhuber et al. (2005) proposed to apply genetic optimisation for learning of supervised EVOLINO (EVolution of recurrent systems with Optimal LINear Output) recurrent neural network (RNN). EVOLINO-based LSTM neural network was approved for prediction not only different sums of sin functions, but also certain contextsensitive grammars and the Mackey-Glass time series. On 
the other hand, sums of sin functions, context-sensitive grammars or the Mackey-Glass time series are not good benchmark for RNN or in particular LSTM networks since even feedforward nets can learn to predict future time series (Schmidhuber et al., 2007).

The accuracy of our tool is based on prediction accuracy of financial time series. Therefore, we applied EVOLINO RNN as the kernel for our financial forecasting framework. Additionally, any prediction is influenced by uncertainty. So, we found that EVOLINO RNN ensemble led to improve quality of time series prediction, where ensemble of predictions is formed as discrete distribution from individual 176 predictors. The block-scheme of EVOLINO RNNbased prediction model presented in Figure 1. The Python programming language based implementation of financial prediction framework can be described by following steps: data collecting; choosing of inputs; computing of prediction ensemble; investment decision making.

Data collecting implemented by using downloads of historical financial markets data from MetaTrader (Alpary). As an neural network input we chose two different historical exchange rates: first input must be historical data of predictable exchange rate and the second input historical data of the same dimension such as XAUUSD (gold price in USA dollars), XAGUSD (Silver price of USA dollars), QM (Oil price in USA dollars) or QG (Gas price in USD dollars). All needed data saved into MySQL database (DB) for a usage in the second step.

Choosing of inputs exploits influence of input data onto prediction quality. Therefore, the python function selects the list of historical data of the first input from exchange rate DB than uses this list for finding a list of second input optimised for best orthogonality, where second list of the same dimension can be shifted in much more bigger list of range 400 points one of XAUUSD, XAGUSD, QM, and QG historical exchange rate data. An orthogonality of the two inputs can be characterised by the closest to zero value of dot product of the input base pairs. The influence of data orthogonality on accuracy and stability of financial market predictions was described in paper (Maknickas \& Maknickiene, 2012), where eight pairs of data intervals with the best orthogonality were investigated for the inputs to the EVOLINO RNN.

Computing of prediction ensemble is most time consumable part of the implementation. Optimal choose is to use limited number of neural networks on hardware we disposed (six nodes of Intel(R) Xeon(R) CPU E5645 @ 2.40 $\mathrm{GHz}$ on the cloud www.time4vps.eu), in case neural networks need several hours of calculations required for a decision making. The selection of the optimum number of ensembles was investigated in earlier works (Maknickiene \& Maknickas, 2013, 2016). The list of all neural network predictors was divided into almost equal sub-lists and every sub-list was calculated on a separate processor node. So calculations of the ensemble of 176 Evolino RNN neural networks predictors take 6.25 hours. The forecast assumes of the discrete distribution of the individual shape. Now we can extract from obtained distribution all actual parameters: mean, median, mode, skewness, kurtosis. meters of it: mean, median, mode, skewness, kurtosis.
Investment decision making. The decision each trade is made by analysing the composition of high and low distributions of expected values. The portfolio is constructed by taking into account the shapes of distributions, probabilities of profit and loss, variation of expected values and period of prediction.

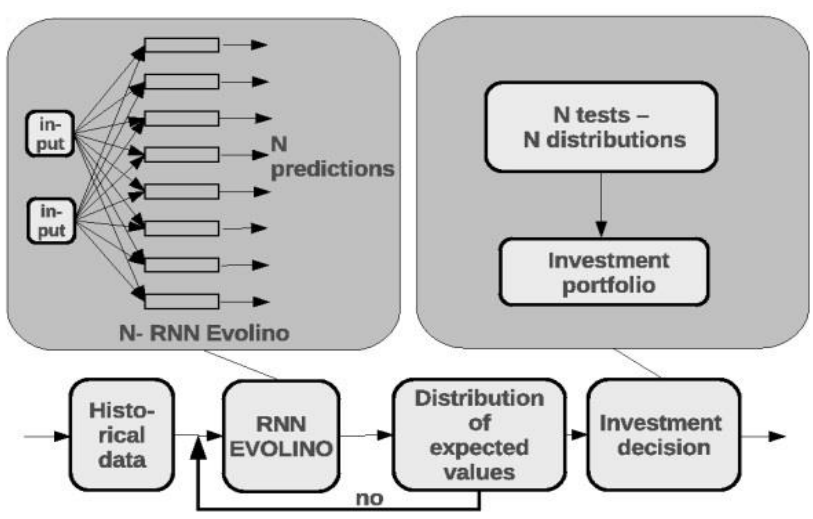

Figure 1. Scheme of Forecasting Model

Distributions are not normal. The dependency of accuracy of prediction on number of Evilino RNN was investigated (Maknickiene \& Maknickas, 2013), where we found that in range of 60-300 NN predictors our ensemble forms multimodal distributions. The decision to invest is then made by taking into account the position of the mode according to the current value. The rule for trading is as follows:

\section{If $f>a$ then buy else sell}

where:

$f$ - is the main mode of forecasting distribution for the second day;

$a$ - is the current value at the moment of trading decision;

'buy', 'sell' - operations in Forex market.

In the case of a high-low strategy predictions are made twice a day: one, with high historical data; the other with low historical data. The trading decision is made by analysing the composition of two distributions. The rules of high-low trading are:

$$
\begin{aligned}
& \text { If, } a<f_{l o w} \text { then buy, } \\
& \text { wait for } a=f_{\text {high }} \text { then sell } \\
& \text { and vice versa: } \\
& \quad \text { If } a>f_{\text {high }} \text { then sell, } \\
& \quad \text { wait for } a=f_{l o w} \text {, then buy, }
\end{aligned}
$$

where:

$a-$ is the current value of exchange rate;

$f_{\text {low }}$ - is the mode of low forecasting distribution;

$f_{\text {high }}$-is the mode of low forecasting distribution;b

When $f_{\text {low }}<\mathrm{a}<f_{\text {high }}$, a decision is more risky and only probabilities of profit and loss may lead to a decision. Predictions of the model based on evolutionary recurrent neural networks and rules of trading are a base for the investment portfolio construction. 
Jelena Stankeviciene, Nijole Maknickiene, Algirdas Maknickas. High-low Strategy of Portfolio Composition using...

\section{Composition of Investment Portfolios}

The simplest way to define the portfolio is to indicate its composition, or to identify the amount of investment instruments included in the portfolio. Markowitz (1952) and Black (1974) proposed the two-dimensional portfolio optimization model. An efficient two-dimensional portfolio (profitability- risk) is defined as a portfolio that has the lowest risk for a given profitability, and maximum return for a given level of risk.

$\left\{\begin{array}{c}\max E R_{p} \\ \min \sigma^{2}\end{array}\right.$

Where,

$$
\begin{aligned}
& E R_{p}=\sum_{i=1}^{n} W_{i} E R_{i,} \\
& \sigma^{2}=\sum_{i=1}^{n} W_{i}^{2} \sigma_{i}^{2}+2 \sum_{i=1}^{n} \sum_{i=j}^{n} W_{i} W_{j} r_{i j} \sigma_{i} \sigma_{j}
\end{aligned}
$$

where $E R_{p}$ is the expected return of the investment portfolio;

$E R_{i}$ is the expected return of the portfolio tool $i$;

$W_{i}$ is the investment on tool $i$;

$W_{i}$ is the investment on tool $j$;

$r_{i j}$ is the correlation coefficient between tools $i$ and $j$;

$\sigma_{i}$ is the standard deviation of tool $i$;

$\sigma_{j}$ is the standard deviation of tool $j$.

Optimization under uncertainty is a decision-making framework to deal with model parameters (mean, expected utility, risk measure etc.) that are unknown or stochastic. The data uncertainty is random and can be explained by some probability distribution. Rutkauskas $(2000,2006)$ used a three-dimensional adequate portfolio. Uncertainty is described through a probability function, which provides good solutions in practice, but suffers from the curse of dimensionality.

Robust optimization is used when data uncertainty is deterministic, but unknown. The solution behaves well under all possible realizations of the data. Uncertainty is not stochastic (no random variables), and is deterministic and based on bounded and convex sets. It is a worst-case scheme but the associated problems can be solved in an efficient way: they are tractable. Now suppose that $E R_{i \mathrm{i}}$ and $D ?_{i}$ are unknown, but not stochastic: it has an interval of bounds. Figure 2 shows a histogram of expected returns and signed bounds of variation.

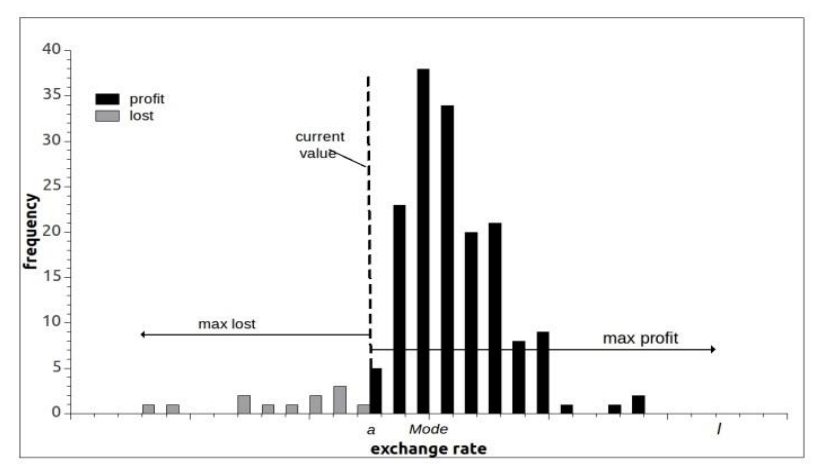

Figure 2. Histogram of Expected Returns and Signed Bound of Variation (Created by Authors)
Then, if the current price is $a$, the probability of profit is

$$
p_{p}=\sum_{a}^{I} E R,
$$

and the probability of loss is:

$$
p_{I}=\sum_{0}^{a} E R=1-p_{p} \text {. }
$$

For a high-low strategy the composition of two distributions is used. Probabilities of profit and loss are:

$$
\begin{aligned}
& p_{p}=\frac{p_{p l o w}+p_{p h i g h}}{2}, \\
& p_{l}=\frac{p_{\text {low }}+p_{\text {lhigh }}}{2}=1-p_{p}
\end{aligned}
$$

The selection of the portfolio, consisting of $i$ exchange rates, is made by this system of equations:

$$
\left\{\begin{array}{l}
\max \sum_{i=1}^{n} W_{i} p_{p i} \\
\min \sum_{i=1}^{n} W_{i} p_{l i}
\end{array}\right.
$$

Calculation of probabilities is integrated into the support system for investor. The high-low prediction time amounts to 12-13 hours. Testing of portfolios was made in a real-time Forex trade practice market without a validation period. Usually, the optimized portfolio is compared with the $1 / \mathrm{N}$ portfolio, where invested funds are divided into equal parts for each $\mathrm{N}$ exchange rate.

\section{Portfolio Composition, Using Parameters of Distributions}

Exchange rates for GBP/AUD (United Kingdom pound and Australian dollar), NZD/CAD (New Zealand dollar and Canadian dollar), EUR/JPY (euro and Japanese yen), USD/CHF (American dollar and Swiss franc), GBP/USD (United Kingdom pound and American dollar) were selected for our portfolio. Historical data are taken from Metatrader Alpari every day. The result of the prediction, using our ensemble of Evolino RNN, is a histogram and its parameters: modes, frequencies, skewness, kurtosis excess, probabilities left and right from mode, and last known value (close). Information from this histogram allows us to make reasonable investment decisions. Calculating the four predictions using the Evolino RNN ensemble takes about 6.25 hours. For daily speculations in the exchange market we calculated two predictions in one day: one with high daily values data; the other with low daily value data. A combination of two distributions appears as a dynamic of the future exchange rate. For 11 August 2014 the calculated predictions are shown in Figures 3-6. The GBP/AUD distribution of expected low values (Figure 3 grey) has a standard deviation equal to 0.0096 ; skewness of 1.57 , excess kurtosis of 0.98 , and main mode of 1.825 . The distribution of high values (Figure 3 black) has a standard deviation equal 0.0405, skewness of 0.76, excess kurtosis is of 1.14, and main mode of 1.825 . 


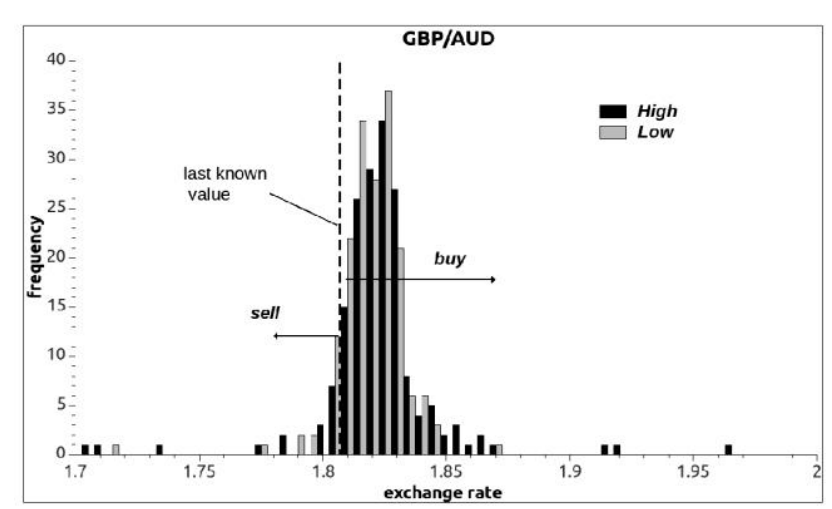

Figure 3. Low and High Histograms of GBP/AUD Prediction

The last known value (closing value the previous day) is 1.80713 , as shown from the left by low and high modes. The decision must be in the buy area, which represents the fact that a high distribution to the right of the last known values is larger than the area to the left. Probabilities of decisions to buy are greater than sell. The decision to sell is risky.

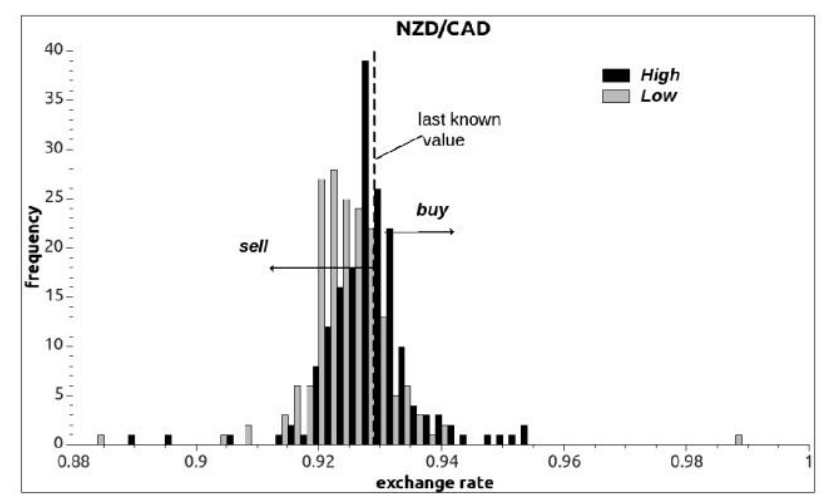

Figure 4. Low and High Histograms of NZD/CAD Prediction

NZD/CAD distribution of expected low values (Figure 4 grey) has standard deviation of 0.0178 , skewness of 1.81 , excess kurtosis of 1.6, and main mode of 0.922. Distribution of high values (Figure 4 black) has a standard deviation 0,0052 , skewness of -0.05 , excess kurtosis of -1.86 , and main mode of 0.928 The last known value (closing value on 8 August 2014) is 0.92772 , as shown on the right from low and high modes. The probability of successful decisions to buy is less than sells. The decision to buy is risky.

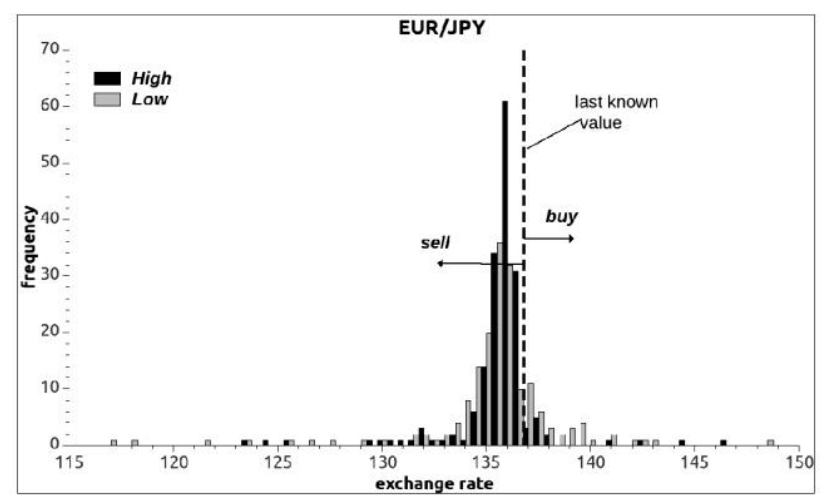

Figure 5. Low and High Histograms of EUR/JPY Prediction
EUR/JPY distribution of expected low values (Figure 5 grey) has standard deviation 2.8461, skewness of 1.31 , excess kurtosis of 0.47 , and main mode of 135.5.

Distribution of high values (Figure 5 black) has standard deviation of 3.52 , skewness of 0.44 , excess kurtosis of -1.62 , and main mode of 136.00 .

The last known value (closing value of previous day) is 136.799 on the right from low and high modes. The decision must be sell. The area, which represents the distribution to the left of the last known values (Figure 5) is larger than the area to the right. So the probability of exchange rates decreasing is more than the probability of an increase in EUR/JPY.

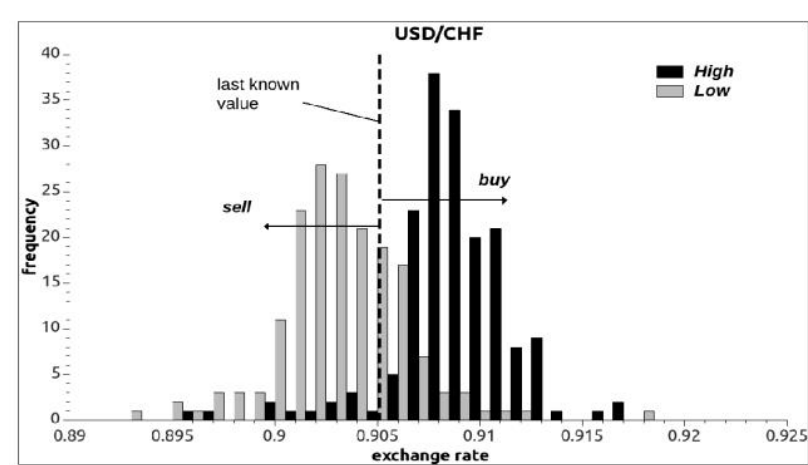

Figure 6. Low and High Histograms of USD/CHF Prediction

USD/CHF distribution of low values (Figure 6 grey) has standard deviation of 0.0029 , skewness of 1.39 , excess kurtosis of 0.62 , and main mode of 0.902 .

Distribution of expected high values (Figure 6 black) has standard deviation of 0.0283 , skewness of 0.94 , excess kurtosis of $-1,22$, and main mode of 0.908 .

Last known value (closing value of previous day) is 0.90514 , between the low and high modes. Area, which represents distribution to the left of the last known values (grey in Figure 6), is approximately equal to the area to the right. So the probability of exchange rates decreasing is approximately equal to the probability of an increase in $\mathrm{USD} / \mathrm{CHF}$

On that day (11 August 2014) the decision to constructing a portfolio was made from the EUR/JPY, USD/CHF, GBP/AUD and NZD/CAD exchange rates. The proportion of the portfolio, taking into account the probabilities (equation (4)) are as follows: 0.3, 0.22, 0.28, 0.20 . Profitability was $6.19 \%$.

Forecasting foreign-exchange-market dynamics using a tool that is able to assess the probability of expected values is stochastically more informative and provides a new quality for investors.

Following this analysis of high-low distributions, two portfolios from four exchange rates were constructed every day for 12 weeks. First, a portfolio was optimized using the rule described by equation (4); and second, a $1 / \mathrm{N}$ portfolio, where invested funds are divided into equal parts for each exchange rate. Next two close-to-close portfolios optimized and 1/N - were constructed, using predictions of one distribution on closing data.

Results of a comparison of the portfolios are shown in Table 1 
Finance.yahoo.com presents these values of 13 weeks' treasury bills day's range $0.01-0.015$ and 52 weeks range of $0.00-0.14$. This was used as a risk-free rate of return for calculating the Sharpe ratio. In our research, the Sharpe ratios of both high-low portfolios are greater than both close-to-close portfolios.

Mean absolute percentage error (MAPE) and other forecasting accuracy calculating methods are based on testing a point prediction. For distributions of expected values, one point, even if it is the main mode, may not clearly reflect the predictive accuracy and reliability. High-low prediction strategies use two main modes, and an investment decision depends on its position. Main mode was used for the MAPE calculation, which determined the decision. The calculated accuracy of one exchange rate high-low prediction is two times better than the close-toclose prediction.

The testing period is too short to accurately assess, evaluate and summarize the profitability and accuracy of portfolio. It would require at least a few years. The long computation time and data harvesting twice a day requires the precise planning of work time. All predictions were obtained in real time, day by day, without a validation period. Trading in real time requires certain personal qualities and discipline. Our prediction tool requires more engineering improvements. However, investment portfolio composition using distribution parameters is much more informative than using separate points. The high-low strategy of portfolio composition is new and very interesting for research, and for creating a support system for investors.

Table 1

Comparison of Portfolios

\begin{tabular}{|c|c|c|c|c|}
\hline \multirow{2}{*}{ Measure } & \multicolumn{2}{|c|}{ High-low } & \multicolumn{2}{c|}{ Close-to-close } \\
\cline { 2 - 5 } & Optimal & $\mathbf{1 / N}$ & Optimal & $\mathbf{1} / \mathbf{N}$ \\
\hline Profitability & $17 \%$ & $15 \%$ & $10 \%$ & $9 \%$ \\
\hline Sharpe ratio & 1.76 & 1.65 & 0.99 & 0.91 \\
\hline MAPE (with main mode) & $0.44 \%$ & $0.44 \%$ & $0.79 \%$ & $0.79 \%$ \\
\hline
\end{tabular}

\section{Conclusions}

The targeting of historical data selection, the coordination of internal model parameters for productive work, the original evolutionary recurrent neural networks architecture, connecting 176 Evolino RNN to one ensemble, and parallel computing are all engineering solutions, which allow the successful application of this tool for forecasting financial markets. The integration of principals of modern portfolio theory to this support system for investor allows for more efficient trading on the currency markets.

The result of our support prediction system is the distribution of expected returns. Distributions have a shape and parameters: mode, standard deviation, skewness, excess kurtosis and others. Prediction based on the distribution of expected values takes information about probability, profitability and riskiness of decision in the financial market. The composition of high-low distributions describes the bias of predicting exchange rates in the future. The position of the current value in respect of high-low distributions defines the probabilities of profit and loss in the prediction. This information leads to decision-making and selection of the investment portfolio.
The paper proposed a comparison and two methods of decision-making:

- close-to-close, based on one distribution of expected values;

- high-low based on the composition of two distributions.

Two strategies of portfolio selection were also compared: $1 / \mathrm{N}$ and optimized. The profitability of optimal portfolios is more than simple division into equal parts, and the high-low method is more profitable than the closeto-close method: $17 \%$ and $15 \%, 10 \%$ and $9 \%$. Sharpe ratios, like measures of efficiency of portfolio selection, are more in the optimal strategy and high-low method: 1.76 and $1.65,0.99$ and 0.91 .

The accuracy of prediction, calculated like the mean absolute percentage error, compared real value (close, high or low) with the mode of close-to close, high or low distributions, and shows that the high-low method is more accurate than close-to close.

Portfolios constructed using probabilities of high-low distributions are more profitable, effective and accurate than portfolios constructed using probabilities of close-toclose data. Optimization of portfolios using information of distributions creates new opportunities for successful trading on the currency markets.

\section{References}

Adcock, C. (2010) Asset pricing and portfolio selection based on the multivariate extended skew-student-t distribution. Annals of Operations Research, 176 (1), 221-234. https://doi.org/10.1007/s10479-009-0586-4

Aguilar-Rivera, R., Valenzuela-Rendon, M., \& Rodriguez-Ortiz, J. J., (2015) Genetic algorithms and Darwinian approaches in financial applications: A survey. Expert Systems with Applications, 42 (21), 7684-7697. https://doi.org/10.1016/j.eswa.2015.06.001

Black, F. (1974). International capital market equilibrium with investment barriers. Journal of Financial Economics, 1 (4), 337-352. https://doi.org/10.1016/0304-405X(74)90013-0 
Campbell, J. T., Sirmon, D., \& Schijven, M. (2015) Fuzzy Logic and the Market: A Configurational Approach to Investor Perceptions of Acquisition Announcements. Academy of Management Journal, 59 (1), $163-187$. https://doi.org/10.5465/amj.2013.0663

Caporin, M., Ranaldo, A., \& De Magistris, P. S. (2013) On the predictability of stock prices: A case for high and low prices. Journal of Banking \& Finance, 37 (12), 5132-5146. https://doi.org/10.1016/j.jbankfin.2013.05.024

Chakraborty, A., Mukherjee, D., Dutta, A., Chakraborty, A., \& Kole, D. K., (2016). An Effective Stock Price Prediction Technique Using Hybrid Adaptive Neuro Fuzzy Inference System Based on Grid Partitioning. In Intelligent Systems Technologies and Applications. Springer international publishing, 275-284. https://doi.org/10.1007/9783-319-23258-4_24

Chen, L., He, S., \& Zhang, S. (2011). Tight bounds for some risk measures, with applications to robust portfolio selection. Operations Research, 59(4), 847-865. https://doi.org/10.1287/opre.1110.0950

Chourmouziadis, K., \& Chatzoglou, P. D. (2016). An intelligent short term stock trading fuzzy system for assisting investors in portfolio management. Expert Systems with Applications, 43, 298-311. https://doi.org/10.10 16/j.eswa.2015.07.063

Corwin, S. A., \& Schultz, P. (2012). A simple way to estimate bid-ask spreads from daily high and low prices. The Journal of Finance, 67 (2), 719-760. https://doi.org/10.1111/j.1540-6261.2012.01729.x

Dupacova, J., \& Kopa, M. (2014). Robustness of optimal portfolios under risk and stochastic dominance constraints. European Journal of Operational Research, 234 (2), 434-441. https://doi.org/10.1016/j.ejor.2013.06.018

Gabaix, X., Gopikrishnan, P., Plerou, V., \& Stanley, H. E. (2003). A the-theory of power-law distributions in financial market fluctuations. Nature, 423(6937), 267-270. https://doi.org/10.1038/nature01624

Gan, K. S., Chin, K. O., Alfred, R., Anthony, P., \& Chang, S. V. (2013, Nov). A review of stock market prediction with artificial neural network (ann). In 2013 ieee international conference Control system, computing and engineering (iccsce), (pp. 477-482).

Garcia-Pedrajas, N., Hervas-Martinez, C., \& Ortiz-Boyer, D. (June, 2005). Cooperative coevolution of articial neural network ensembles for pattern classification. Evolutionary Computation, IEEE Transactions on, 9 (3), $271-302$.

Hautsch, N., Malec, P., \& Schienle, M. (2013). Capturing the zero: a new class of zero-augmented distributions and multiplicative error processes. Journal of Financial Econometrics, nbt002.

Horst, E. T., Rodriguez, A., Gzyl, H., \& Molina, G. (2012). Stochastic volatility models including open, close, high and low prices. Quantitative Finance, 12 (2), 199\{212. https://doi.org/10.1080/14697688.2010.492233

Huang, X. (2011). Minimax mean-variance models for fuzzy portfolio selection. Soft Computing, 15(2), 251-260. https://doi.org/10.1007/s00500-010-0654-3

Inuiguchi, M., \& Ramık, J. (2000). Possibilistic linear programming: a brief review of fuzzy mathematical programming and a comparison with stochastic programming in portfolio selection problem. Fuzzy Sets and Systems, 111(1), 328. https://doi.org/10.1016/S0165-0114(98)00449-7

Leangarun, T., Tangamchit, P., \& Thajchayapong, S. (2016), February. Stock price manipulation detection using a computational neural network model. In 2016 Eighth International Conference on Advanced Computational Intelligence (ICACI), IEEE 337-341.

Li, J., \& Miller, N. C. (2015). Foreign exchange market inefficiency and exchange rate anomalies. Journal of International Financial Markets, Institutions and Money, 34, pp. 311-320. https://doi.org/10.1016/j.intfin.20 14.12.001

Liesio, J., \& Salo, A. (2012). Scenario-based portfolio selection of investment projects with incomplete probability and utility information. European Journal of Operational Research, 217(1), 162-172. https://doi.org/10.1016/j.ejor. 2011.08.025

Lozza, S. O., Angelelli, E., \& Toninelli, D. (2011). Set-portfolio selection with the use of market stochastic bounds. Emerging Markets Finance and Trade, 47, 5-24. https://doi.org/10.2753/REE1540-496X4706S501

Maknickas, A., \& Maknickiene, N. (2012, Oct). Influence of data orthogonality to accuracy and stability of financial market predictions. In 4th international conference on neural computation theory and applications (NCTA 2012) (pp. 616-619). Barcelona, Spain.

Maknickiene, N., \& Maknickas, A. (2013). Investigation of prediction capabilities using rnn ensembles. In IJCCI 2013: 5th International Joint Conference on Computational Intelligence, 20th to 22nd September, 2013, Vilamoura, Portugal (pp. 391-395).

Maknickiene, N., \& Maknickas, A. (2016). Prediction Capabilities of Evolino RNN Ensembles. In Computational Intelligence (pp. 473-485). Springer International Publishing. https://doi.org/10.1007/978-3-319-23392-5_26

Markowitz, H. (1952). Portfolio selection. The journal of finance, 7 (1), 77-91. https://doi.org/10.1111/j.1540- 
Jelena Stankeviciene, Nijole Maknickiene, Algirdas Maknickas. High-low Strategy of Portfolio Composition using... 6261.1952.tb01525.x

Nguyen, H., \& Chan, C. (2004). Multiple neural networks for a long term time series forecast. Neural Computing \& Applications, 13 (1), 90-98. https://doi.org/10.1007/s00521-003-0390-z

Rimeh, E. F., Abdelaziz, F. B., \& Belaid, A. (2013, April). Scenario generation for multi-objective stochastic portfolio selection. In 5th international conference on Modelling, simulation and applied optimization (icmsao), 2013. pp. 1(6). https://doi.org/10.1109/icmsao.2013.6552694

Rocco, M. (2014). Extreme value theory in finance: A survey. Journal of Economic Surveys, 28(1), 82-108. https://doi.org/10.1111/j.1467-6419.2012.00744.x

Rutkauskas, A. V. (2000). Formation of adequate investment portfolio for stochasticity of profit possibilities. Property management, 4(2), 100-115.

Rutkauskas, A. V. (2012). Using sustainability engineering to gain universal sustainability efficiency. Sustainability, 4 (6), 1135-1153. https://doi.org/10.3390/su4061135

Rutkauskas, A. V. (2006). Adekvaciojo investavimo portfelio anatomija ir sprendimai panaudojant imitacines technologijas. Ekonomika, 75, 52-76. Available from http://www.leidykla.eu/fileadmin/Ekonomika/75/ Aleksandras Vytautas Rutkauskas.pdf

Rutkauskas, A. V., \& Lapinskaite-Vvohlfahrt, I. (2010, May 13-14). Marketing finance strategy based on effective risk management. In The 6th International Scientific Conference 'Business and Management 2010': selected papers Technika, Vol. 1, pp. 162-169. https://doi.org/10.3846/bm.2010.023

Rutkauskas, A. V., Miecinskiene, A., \& Stasytyte, V. (2008). Investment decisions modelling along sustainable development concept on financial markets. Technological and Economic Development of Economy, 14(3), 417427. https://doi.org/10.3846/1392-8619.2008.14.417-427

Rutkauskas, A. V., \& Stasytyte, V. (2011). Optimal portfolio search using efficient surface and three-dimensional utility function. Technological and Economic Development of Economy, 17(2), 305-326. https://doi.org/10.3846/ 20294913.2011.580589

Schmidhuber, J., Wierstra, D., Gagliolo, M., \& Gomez, F. (2007). Training recurrent networks by evolino. Neural Computation, 19 (3), 757-779. https://doi.org/10.1162/neco.2007.19.3.757

Schmidhuber, J., Wierstra, D., \& Gomez, F. (2005). Modeling systems with internal state using evolino. In proc. of the 2005 conference on genetic and evolutionary computation (gecco) (pp. 1795-1802). Washington: ACM Press, New York, NY, USA.

Siwek, K., Osowski, S., \& Szupiluk, R. (2009). Ensemble neural network approach for accurate load forecasting in a power system. International Journal of Applied Mathematics and Computer Science, 19 (2), $303-315$. https://doi.org/10.2478/v10006-009-0026-2

Tanaka, H., Guo, P., \& Turksen, I. B. (2000). Portfolio selection based on fuzzy probabilities and possibility distributions. Fuzzy sets and systems, 111(3), 387-397. https://doi.org/10.1016/S0165-0114(98)00041-4

Uchigaki, S., Uchida, S., Toda, K., \& Monden, A. (Aug. 2012). An ensemble approach of simple regression models to cross-project fault prediction. In 13th acis international conference on Software engineering, artificial intelligence, networking and parallel distributed computing (snpd), 2012 (pp.476-481).

Wierstra, D., Gomez, F. J., \& Schmidhuber, J. (2005). Evolino: Hybrid neuroevolution: optimal linear search for sequence learning. In Proceedings of the 19th international joint conference on artificial intelligence (ijcai), (pp. 853-858). Edinburgh.

Wu, C., Luo, P., Li, Y., \& Chen, K., (2015). Stock Price Forecasting: Hybrid Model of Artificial Intelligent Methods. Inzinerine Ekonomika-Engineering Economics, 26(1), 40-48. https://doi.org/10.5755/j01.ee.26.1.3836

Zaremba, A., Konieczka, P., Okon, S., \& Nowak, A. (2016). The Low Price Anomaly and the Intriguing Case of the Polish Stock Market. Inzinerine Ekonomika-Engineering Economics, 27(2), 163-174. https://doi.org/10.5755/ j01.ee.27.2.13490

Zhou, Z. H., Wu, J., \& Tang, W. (2002). Ensembling neural networks: many could be better than all. Artificial intelligence, 137(1), 239-263. https://doi.org/10.1016/S0004-3702(02)00190-X

Ziemba, W. T., \& Mulvey, J. M. (1998). Worldwide asset and liability modeling (Vol. 10). Cambridge University Press. pp, 665.

Ziemba, W. T., \& Vickson, R. G. (1975). Stochastic optimization models in finance. Academic Press New York, pp. 736.

The article has been reviewed.

Received in August, 2016; accepted in April, 2017. 